\title{
Impact of long-term and short-term therapies on seminal parameters
}

\author{
Jlenia Elia, Norina Imbrogno, Michele Delfino, Rossella Mazzilli, Vincenzo Spinosa, \\ Fernando Mazzilli \\ Department of Clinical and Molecular Medicine, Sant'Andrea Hospital, Unit of Andrology, \\ University of Rome "Sapienza", Rome, Italy.
}

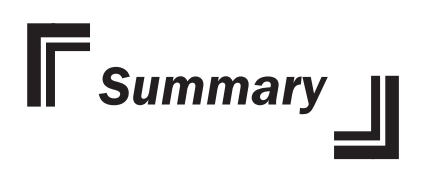

Aim: The aim of this work was: i) to evaluate the prevalence of male partners of subfertile couples being treated with long/short term therapies for non andrological diseases; ii) to study their seminal profile for the possible effects of their treatments on spermatogenesis and/or epididymal maturation.

Methods: The study group was made up of 723 subjects, aged between 25 and 47 years. Semen analysis was performed according to World Health Organization (WHO) guidelines (1999). The Superimposed Image Analysis System (SIAS), which is based on the computerized superimposition of spermatozoa images, was used to assess sperm motility parameters. Results: The prevalence of subjects taking pharmacological treatments was 22.7\% (164/723). The prevalence was $3.7 \%$ (27/723) for the Short-Term Group and 18.9\% (137/723) for the Long-Term Group. The subjects of each group were also subdivided into subgroups according to the treatments being received. Regarding the seminal profile, we did not observe a significant difference between the Long-Term, Short-Term or the Control Group. However, regarding the subgroups, we found a significant decrease in sperm number and progressive motility percentage in the subjects receiving treatment with antihypertensive drugs compared with the other subgroups and the Control Group.

Conclusions: In the management of infertile couples, the potential negative impact on seminal parameters of any drugs being taken as Long-Term Therapy should be considered. The pathogenic mechanism needs to be clarified.

KEY WORDS: Male fertility; Semen, Long-Term Therapy; Short-Term Therapy.

\section{INTRODUCTION}

Pharmacological therapy taken by the male partners of subfertile couples could represent a pathogenic factor that may negatively influence seminal parameters. The potential negative effects could impact on spermatogenesis, thus affecting the sperm number and morphology, and also epididymal maturation, which could affect progressive sperm motility.

In the literature, there are few studies regarding the relationship between the effects of Long-Term and ShortTerm drug therapies and seminal parameters; moreover, such studies usually consider only a single class of drugs (such as statins, antihypertensives, etc.).
Concerning Long-Term therapies, one of the first papers on the effects of drug treatment on seminal parameters concerned sulfasalazine, generally used for intestinal illness. Toth et al. (1) and Cosentino et al. (2) reported a reduction in progressive sperm motility and an increase in atypical forms.

Subsequently, there were other papers, which concerned antiepileptics, antiretrovirals, alpha-lytics and statins. In particular, Chen et al. (3) showed the negative effects "in vitro" on sperm motility of carbamazepine, phenytoin, valproate and phenobarbital. These data were also confirmed in other studies (4-6). In addition, several studies (7-8) 
suggested an enhancement in semen quality parameters following the cessation of pharmacological therapies. Other Authors showed a reduction of progressive sperm motility caused by antiretroviral drugs (9), by statin treatment (10) and by tamsulosin (11), that affect also sperm number and atypical forms.

Regarding Short-Term therapies, there are very few reports in the literature: Schlegel et al. (12) defined antibiotics (nitrofurans, sulfasalazine, minocycline) as "potential hazards to male fertility" owing to potentially dangerous effects on sperm concentration. Other studies regard the possible interaction between PDE5-inhibitors and semen parameters; however, there are conflicting data about their action. Aversa et al. (13) observed that sildenafil did not change seminal parameters; on the other hand, Pomara et al. (14) observed an increase of progressive sperm motility in subjects treated with sildenafil $(50 \mathrm{mg})$, while the use of tadalafil $(20 \mathrm{mg}$ ) produced a decrease in semen quality. Finally, Jarvi et al. (15) studied the possible effects of daily treatment for 6 weeks with vardenafil and tadalafil; in both cases, no changes were observed on seminal parameters.

The aim of this work was: i) to evaluate the prevalence of male partners of subfertile couples being treated with long/short term therapies for non andrological diseases; ii) to study their seminal profile for the possible effects of their treatments on spermatogenesis and/or epididymal maturation.

\section{MATERIALS AND METHOdS}

\section{Subjects}

The clinical study was conducted according to the Hospital Ethics' Committee Guidelines.

The study group was made up of 723 subjects, aged between 25 and 47 years, who were referred to our Andrology Unit from December 2007 to December 2011 for various andrological examinations. A full medical history was taken afterthat the patients underwent a diagnostic and therapeutic program comprising: clinical and seminal examination and hormonal profile. All subjects with hormonal alterations, treated cryptorchidism, previous testicular trauma, seminal obstructions or genetic alterations were excluded from the study.

\section{Semen analysis}

Semen samples were collected by masturbation after a sexual abstinence period of 3-5 days. After liquefaction (for $15-30 \mathrm{~min}$ at $37^{\circ} \mathrm{C}$ ), the semen samples were stored in a controlled incubator at $37^{\circ} \mathrm{C}$ within 60 min of ejaculation and then analyzed according to World Health Organization (WHO) guidelines 1999 (16). The Superimposed Image Analysis System (SIAS) (Delta Sistemi, Rome Italy), which is based on computerized image superimposition, was used to asses sperm motility parameters $(17,18)$.

Sperm morphology was assessed using the BryanLeishman stain technique and examined at a magnification of 1000x, with an Olympus CX 31 light microscope, using a micrometric scale. All the subjects had at least 2 standard semen analyses and the mean of the results obtained was established for each seminal parameter; at least 200 spermatozoa were evaluated.

The total subjects were then subdivided into two groups, based on the pharmacological therapies being taken:

- Long-Term Therapy Group (more than 6 months);

- Short-Term Therapy Group (more than 7 days and less than 15 days).

\section{Statistical analysis}

Results are expressed as percentages, mean values and standard deviations. The Fisher exact test and the Student t-test for independent samples were performed to compare the means of the two distributions. A $p$ value $<0.05$ was considered significant.

\section{RESULTS}

The prevalence of subjects who were taking pharmacological treatments was $22.7 \%$ (164/723). In particular, the prevalence was $3.7 \%(27 / 723)$ for the Short-Term Therapy Group and 18.9\% (137/723) for the Long-Term Therapy Group. Subsequently, the subjects of each Group were further subdivided into subgroups, according to the treatment being taken. The remaining subjects that were not taking any pharmacological therapies (559/723; 77.3\%) were employed as a Control Group.

\section{The Short-Term Therapy Group}

The subjects in Short-Term Therapy were subdivided as follows: antibiotics 2.3\% (17/723); antinflammatory $1.1 \%(8 / 723)$ and PDE5-inhibitors 0.3\% (2/723); (Table 1). Regarding the seminal profile, we did not observe any significant differences between the ShortTerm Group and the Control Group; the same was true for the subgroups.

\section{The Long-Term Therapy Group}

The subjects in Long-Term Therapy Group were subdivided into the following subgroups (Table 1): a) antipsy-

Table 1.

Total subjects in pharmacological treatments (Short- and Long-Term Therapy Groups) and Control Group.

\begin{tabular}{|c|c|c|c|c|c|c|c|c|c|c|}
\hline \multicolumn{3}{|c|}{$\begin{array}{c}\text { Short -Term Therapy Group } \\
\text { n. } 27 / 723(3.7 \%)\end{array}$} & \multicolumn{7}{|c|}{$\begin{array}{c}\text { Long-Term Therapy Group } \\
\text { n. } 137 / 723(18.9 \%)\end{array}$} & \multirow{2}{*}{$\begin{array}{l}\text { Control Group } \\
\text { n. 559/723 } \\
\text { No therapy }\end{array}$} \\
\hline Antibiotics & $\begin{array}{c}\text { Anti- } \\
\text { inflammatory }\end{array}$ & $\begin{array}{l}\text { PDE-5 } \\
\text { Inhibitors }\end{array}$ & $\begin{array}{l}\text { Antipsycotic/ } \\
\text { antiepileptic }\end{array}$ & Antihypertensive & Antihistamine & $\begin{array}{l}\text { Gastro- } \\
\text { protective }\end{array}$ & Hormone & Miscellaneous & Combined & \\
\hline ก. 17 & ก. 8 & ก. 2 & ก. 29 & ก. 19 & ก. 18 & ก. 12 & ก. 8 & ก. 17 & n. 34 & ก. 559 \\
\hline$(2.4 \%)$ & $(1.1 \%)$ & $(0.3 \%)$ & $(4.0 \%)$ & (2.6\%) & $(2.5 \%)$ & $(1.7 \%)$ & $(1.1 \%)$ & $(2.3 \%)$ & $(4.7 \%)$ & $(77.3 \%)$ \\
\hline
\end{tabular}


chotic and antiepileptic drugs: 4.0\% (29/723 cases); b) antihypertensive drugs: $2.6 \%$ (19/723 cases); c) antihistaminic drugs: $2.5 \%$ (18/723 cases); d) gastroprotective drugs $1.7 \%$ (12/723 cases); e) hormone $1.1 \%$ (8/723 cases); f) miscellaneous (antiretroviral, statins, oral antidiabetic drugs or anticoagulants, etc) $2.3 \%$ (17/723 cases); g) combined therapy (antihypertensive and gastroprotective drugs; antipsychotic and metabolic drugs; antihypertensive, anticoagulant and statin drugs): $4.7 \%$ (34/723 cases).

Regarding the seminal profile, we did not observe any significant differences between the Long-Term Therapy Group and the Control Group (Figure 1).

Figure 1.

Semen parameters in Long-Term Therapy Group and in Control Group.

Boxes indicate $25^{\text {th }}$ and $75^{\text {th }}$ percentiles while the horizontal line within the box indicates the $50^{\text {th }}$ percentile value (median).

Vertical lines give $10^{\text {th }}$ and $90^{\text {th }}$ percentile limits of the data, while single points indicate extreme values outside this range.

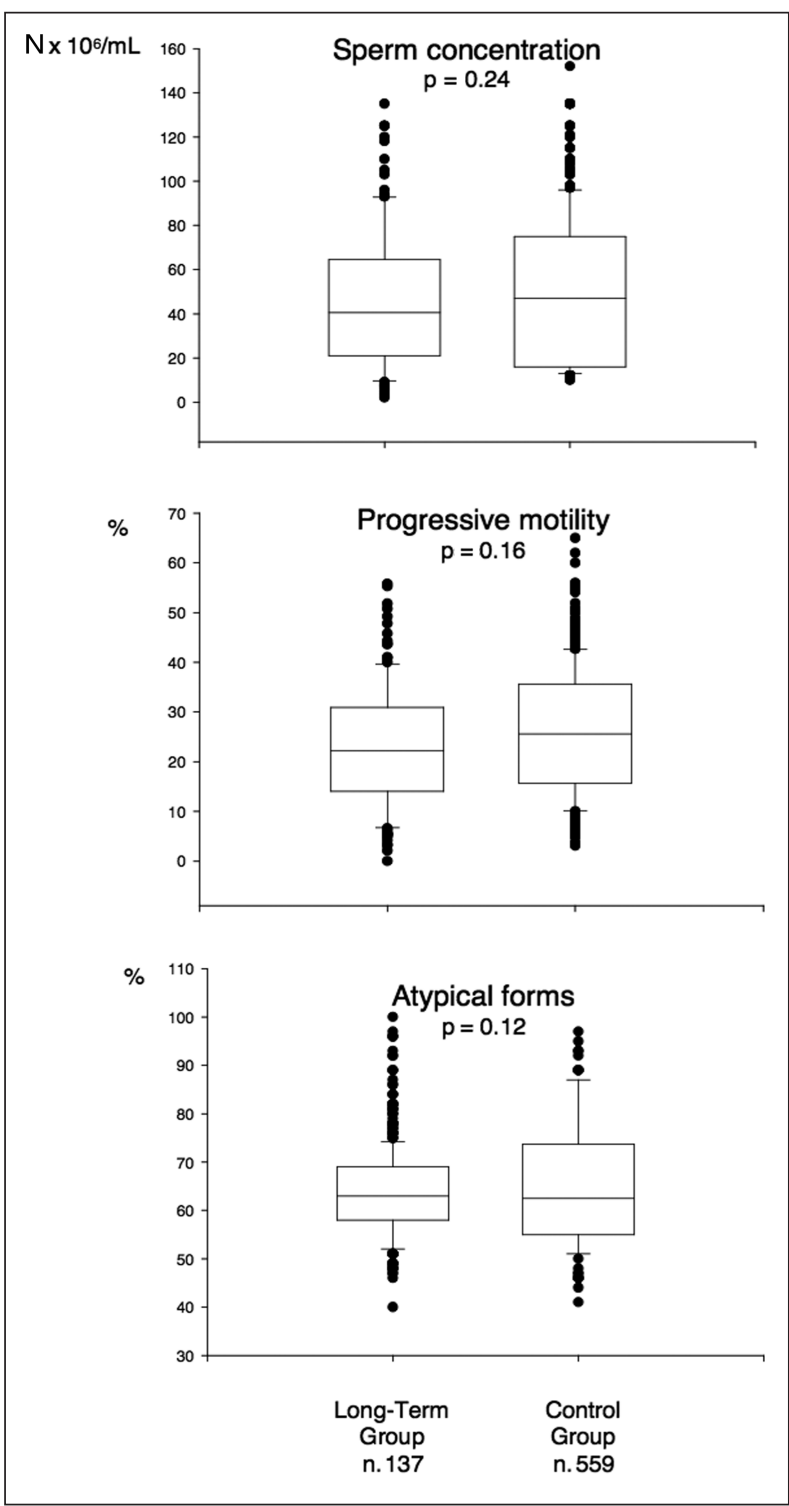

On the other hand, regarding the subgroups, we found a significant decrease in sperm number and progressive motility percentage in subjects treated with antihypertensive drugs compared with the other Long-Term Therapy subgroups $(\mathrm{p}<0.05)$ (Figure 2).

Figure 2.

Semen parameters in Long-Term Therapy Subgroups and Control Group.

A) Control Group; B) Antipsychotic/Antiepileptic; C) Antihypertensive; D) Antihistamine; E) Gastroprotective;

F) Hormone; G) Miscellaneus; H) Combined. * $p<0.05$ vs control group.

Boxes indicate $25^{\text {th }}$ and $75^{\text {th }}$ percentiles while the horizontal line within the box indicates the $50^{\text {th }}$ percentile value (median).

Vertical lines give $10^{\text {th }}$ and $90^{\text {th }}$ percentile limits of the data, while single points indicate extreme values outside this range.

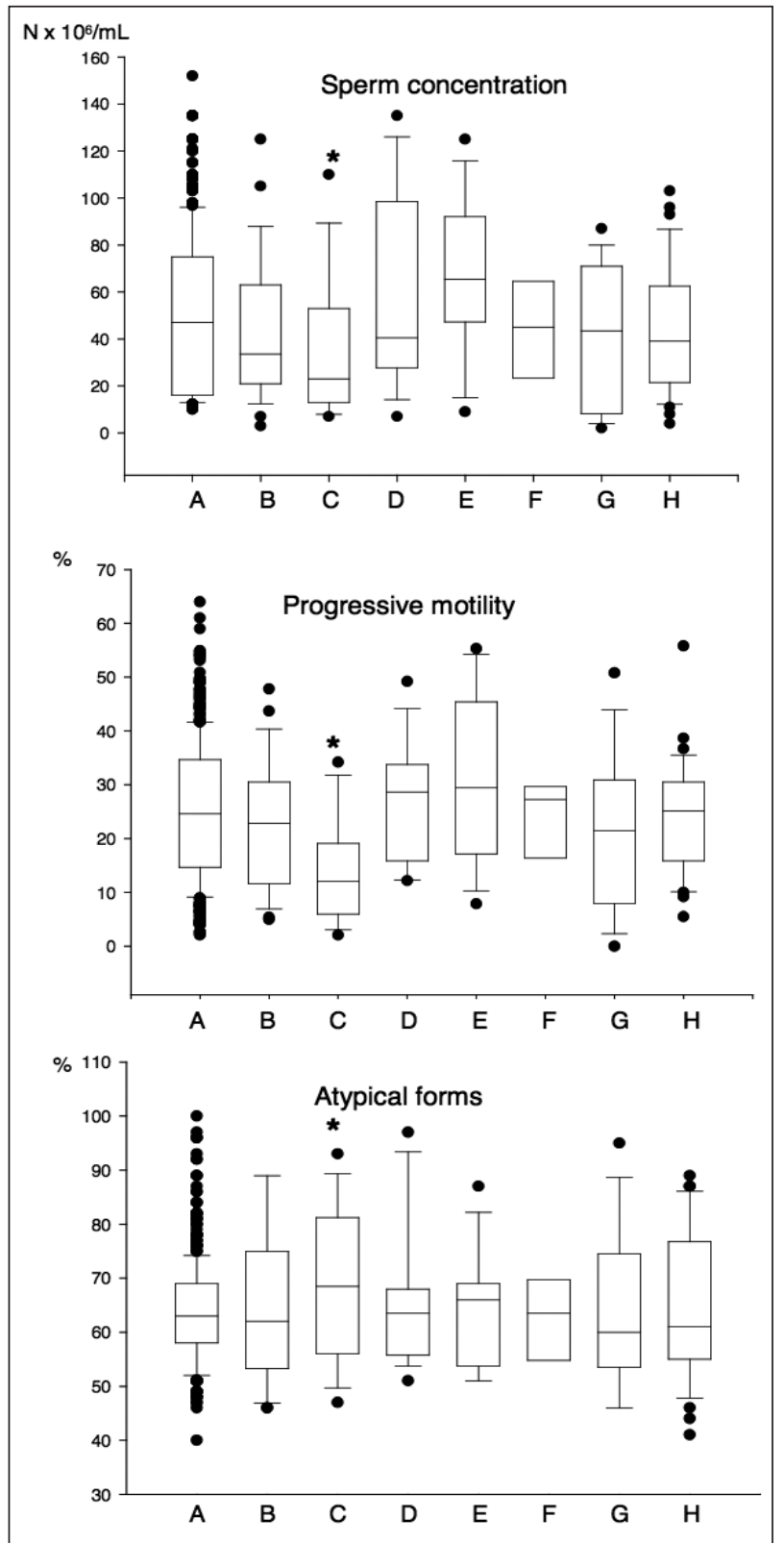




\section{Discussion}

In this study we considered the prevalence of male partners of subfertile couples under Long-Term and ShortTerm pharmacological treatments for non andrological diseases and the possible effects of such treatment on seminal parameters.

Regarding the first, the prevalence of pharmacological treatments identified was $22.7 \%$, almost double that of Hayashi's data (19). It is a remarkable prevalence, especially in such a relatively young population. We differentiated in Short-Term treatment for the possible effects only on epididymal maturation and Long-Term for possible effects on the process of spermatogenesis and/or epididymal maturation. The prevalence found was 3.7\% in the Short-Term Group and mainly involved the use of antibiotics and antinflammatory medication and only minimally the use of PDE5 inhibitors.

In subjects taking Long-Term Therapy, the prevalence observed was $18.9 \%$; this concerned the use of various classes of drugs, including antipsychotic, antiepileptic, antihypertensive, antihistamine medications and also drugs associations. Regarding the seminal profile, we did not observe any significant differences between the ShortTerm Therapy Group, or the subgroups, vs the Control Group. Regarding antinflammatory medication, this is not surprising since they are commonly used for the treatment of genital tract inflammation. However, even antibiotics did not appear to have a negative impact on seminal parameters. The number of subjects taking PDE5 inhibitors was too small to have a statistical significance. Also the Long-Term Group did not show any significant variations compared with the Control Group. On the other hand, the Long-Term subgroup treated with antihypertensive drugs (calcium channel blockers, beta blockers, angiotensin converting enzyme inhibitors) showed a significant decrease in sperm number and progressive motility percentage compared with the other Long-Term Therapy subgroups and the Control Group. The possible pathogenic mechanism may be an alteration in local blood flow, also at the hemato-testicular barrier, which would produce a reduction of the nutrients needed in spermatogenesis, or perhaps direct damage to the epididymis, which would inhibit kinetic sperm properties and then motility.

In conclusion, Long-Term drug therapy is a factor that should always be taken into consideration in the management of infertile couples, owing to the potential negative impact of such treatment on seminal parameters. The pathogenic mechanisms involved need to be clarified.

\section{REFERENCES}

1. Toth A. Reversible toxic effect of salicylazosulfapyridine on semen quality. Fertil Steril. 1979; 31:538-40.

2. Cosentino MJ, Chey WY, Takihara H, Cockett AT. The effects of sulfasalazine on human male fertility potential and seminal prostaglandins. J Urol. 1984; 132:682-6.

3. Chen SS, Shen MR, Chen TJ, Lai SL. Effects of antiepileptic drugs on sperm motility of normal controls and epileptic patients with long-term therapy. Epilepsia. 1992; 33:149-53.

4.Taneja N, Kucheria K, Jain S, Maheshwari MC. Effect of phenytoin on semen. Epilepsia. 1994; 35:136-40.
5. Roste LS, Tauboll E, Haugen TB, et al. Alterations in semen parameters in men with epilepsy treated with valproate or carbamazepine monotherapy. Eur J Neurol. 2003; 10:501-6.

6. Isojarvi JI, Lofgren E, Juntunen KS, et al. Effect of epilepsy and antiepileptic drugs on male reproductive health. Neurology. 2004; 62:247-53.

7. Yerby MS, McCoy GB. Male infertility: possible association with valproate exposure. Epilepsia. 1999; 40:520-1.

8. Hayashi T, Yoshinaga A, Ohno R, et al. Asthenozoospermia: possible association with long-term exposure to an anti-epileptic drug of carbamazepine. Int J Urol. 2005; 12:113-4.

9. van Leeuwen E, Wit FW, Repping S, et al. Effects of antiretroviral therapy on semen quality. AIDS. 2008; 22:637-42.

10. Dobs AS, Schrott H, Davidson MH, et al. Effects of high-dose simvastatin on adrenal and gonadal steroidogenesis in men with hypercholesterolemia. Metabolism. 2000; 49:1234-8.

11. Hellstrom WJ, Sikka SC. Effects of alfuzosin and tamsulosin on sperm parameters in healthy men: results of a short-term, randomized, double blind, placebo-controlled, crossover study. J Androl. 2009; 30:469-74.

12.Schlegel PN, Chang TS, Marshall FF. Antibiotics: potential hazards to male fertility. Fertil Steril. 1991; 55:235-42.

13. Aversa A, Mazzilli F, Rossi T, et al. Effects of sildenafil (Viagra) administration on seminal parameters and post-ejaculatory refractory time in normal males. Hum Reprod. 2000; 15:131-4.

14. Pomara G, Morelli G, Canale D, et al. Alterations in sperm motility after acute oral administration of sildenafil or tadalafil in young, infertile men. Fertil Steril. 2007; 88:860-5.

15. Jarvi K, Dula E, Drehobl M, et al. Daily vardenafil for 6 months has no detrimental effects on semen characteristics or reproductive hormones in men with normal baseline levels. J Urol. 2008; 179:1060-5.

16. World Health Organization. Laboratory manual for the examination of human semen and sperm-cervical mucus interaction. $4^{\text {rd }}$ ed. New York: Cambridge University Press. 1999.

17. Mazzilli F, Rossi T, Sabatini L, Dondero F. Superimposed image analysis system (SIAS) software: a new approach to sperm motility assessment. Fertil Steril. 1995; 64:653-6.

18. Mazzilli F, Rossi T, Delfino M, Nofroni I. Application of the upgraded image superimposition system (SIAS) to the assessment of sperm kinematics. Andrologia. 1999; 31:187-94.

19. Hayashi T, Miyata A, Yamada T. The impact of commonly prescribed drugs on male fertility. Hum Fertil. 2008; 11:191-6.

\section{Correspondence}

Jlenia Elia, MD

Norina Imbrogno, MD

Michele Delfino, MD

Rossella Mazzilli, MD

Vincenzo Spinosa, MD

Sant'Andrea Hospital, Unit of Andrology, University of Rome "Sapienza" Via di Grottarossa 1035 - 00189 Roma, Italy

Fernando Mazzilli, MD (Corresponding Author) Professor Sant'Andrea Hospital, Unit of Andrology University of Rome "Sapienza", via di Grottarossa 1035 - 00189 Roma, Italy fernando.mazzilli@uniromal.it 